\title{
Should parental decision override best interest of a handicapped child? A case illustration in a Malaysian child with Down Syndrome
}

\section{Fahisham Taib ${ }^{1}$, Nur Arzuar Abdul Rahim ${ }^{1}$, Mohd Rizal Mohd Zain ${ }^{1}$, Mohamad Ikram Ilias ${ }^{1}$, Nik Mohd Rizal Mohd Fakri ${ }^{2}$ Zabidi Azhar Hussin ${ }^{1}$}

${ }^{1}$ Department of Paediatrics, Universiti Sains Malaysia, Kubang Kerian, Malaysia. ${ }^{2}$ Department of Medical Education, Universiti Sains Malaysia, Kubang Kerian, Malaysia

\section{ARTICLE INFO}

Received : : 11/12/2014

Accepted : :07/01/2015

Published : : 25/03/2015

\section{KEYWORD}

Chronic illness

Paediatrics

Decision making

Doctor-Parents relationship

\section{ABSTRACT}

The paper discusses on the complexity of the issues surrounding a patient with subluxation of cervical spine in a Down syndrome child. Several relevant issues are discussed including consent in a minor, conflicting decision making between parents and doctors, end-of-life issues, supporting handicapped child with minimal co-morbidities, community ethics, neglect of care by the caregiver and decision making after allowing zonal of parental discretion. Despite the difficulties surrounding parental actions, there are still ethical priorities which have to be considered individually to alleviate the suffering of the patients and the family members. Dealing with patients with chronic illnesses is a challenge for any medical doctors. The case warrants sensitive approach to allow appropriate respect for parental decision despite in disagreement with the clinical team. The term 'zone of parental discretion' refers to a controversial area of decision making; and has still many potential conflicts on day to day clinical cases, especially among the conservative society in the East Coast of Peninsular Malaysia.

(c) Medical Education Department, School of Medical Sciences, Universiti Sains Malaysia. All rights reserved.

CORRESPONDING AUTHOR: Dr Fahisham Taib, Department of Paediatrics, School of Medical Sciences, Universiti Sains Malaysia, 16150 Kubang Kerian, Kelantan. Email: fahisham@gmail.com

\section{Introduction}

Clinical context can be challenging when managing paediatric patients with chronic conditions. Many factors have to be considered to ensure effective communication thus improving parental and doctors relationship. Managing these chronic illnesses in children requires physicians to respect parental roles as the sole and legal decision maker for their children. Guided decision making is vital to ensure participation from caregivers and the outcome is in accordance to a valid ethical principles. In certain scenarios, allowing zonal of parental discretion is seen as the way forward to reach mutually agreed decision between the parents and healthcare professionals. This is particularly relevant to many contexts, such as refusal routine vaccination or lumbar puncture, where such decision is tolerated to avoid hostile doctor-parent relationship.

\section{Case}

A 5-year old Down syndrome girl with atrial septal defect (ASD) presented with the history of repeated falls. She was brought to the hospital with pallor, increasing breathing effort and inability to move by her father after the third episodes. She had 2 previous histories of falls earlier in the year with reported of mild neurological deficit. Despite her known 
underlying trisomy 21, she has normal physical ability and delayed only in speech and learning. On examination, she was hypotonia, with muscle power of $0 / 5$, brisk upper and lower limbs reflexes with unsustained clonus. She was noted to have laboured breathing thus intubation, ventilated and aggressive antibiotics were performed. Computerised Tomography(CT) imaging showed subluxation of cervical spine between C1 and C2 which led to her underlying neurological deficit. She was planned for surgical stabilization of cervical spine following a family conference with the healthcare team.

However, her parents decided against having spinal decompression despite multidisciplinary team consensus. As a result, she remained ventilated through tracheostomy and planned for home ventilation. The family from middle class background with both parents working as secondary school teachers. Prior to the discharge home planning, there were multiple issues encountered - feeding via Ryles tube due to uncertain swallowing mechanic, failure to thrive primarily due to parental decision not to follow dietetic input, inadequate personnel to support patient in the community, concern over complications such as pressure sores and technicality of parental ability to using intensive care and nursing equipment.

\section{Ethical issues discussion}

The case demonstrates many dilemmas faced by paediatricians when dealing with these challenging issues.

a) In mildly handicapped Down syndrome patients with minor medical issues, when do we decide for all out treatment?

b) Should there be a potentially life-saving treatment and parents opted against doctors' opinion, what are the moral issue and guide in this scenario?

c) Is it right to allow parents to make clinical decision?

d) Is it considered neglect for parents who brought their children late and refusing for potentially successful medical intervention? e) What would be future issues regarding end of life issues, future treatment and support in the community?

\section{Discussion}

The case highlights a diverse ethical, moral and human rights issue for a handicapped child in a conservative Malaysian society. Malaysia is a nation famous with its multi faith, racial and cultural background. Even among similar cultural and religious belief, there can be differences in the customary practices. Understanding local cultural and family context perhaps can give a better idea of various interventional requirements that may be a norm for a family or individual.

\section{Option for treatment in mildly handicapped children}

As healthcare professional, one of the most important aspects in ethical decision is to respect autonomy of the patients. In children, autonomy is usually taken by the main caregivers of the children because of their incompetency. Children of younger age may not be able to understand the concept of giving consent for investigation and treatment. The capacity and competency of a child is usually decided by proxy, either by parents, caregiver or the court. In the case of intellectually disabled child such as in our scenario, a Down syndrome without major cardiac defect, it has to take into account of the best interest of her condition. The judicial best interest in the incompetent patients is rather uncertain[1]. Best interest, however, has become unrealistic because it is related to interest of other resources, parental or family interests. Interest of a handicapped child can be explored into assessing the benefits and burdens against child's future life, the meaning of her life and further suffering caused by the action. This can be simplified whether the child has abolition of interest, increased in the burden due to underlying condition or reduced benefits from something which is objectively valued as a human in life. 
In Islamic perspective, we are governed by the principles of maqasid syariah (the purpose of syariah) and qawaid al-fiqiyyah(Islamic legal maxim). Preservation of life is considered high as guideline for Muslim practitioners. Parallel to that, the purpose of helping patients must be based of principles of motives - to save human life. These two values, namely from ethical and Islamic views, have influenced the decision made for the patient to ensure appropriate steps undertaken according to the best moral value and clinical judgment.

\section{Moral judgment in conflicting doctors and caregivers decision}

Conflicting decision can be difficult to remedy. Decision made should be agreed mutually between both parties - doctors and caregivers alike. Experience and authority of a medical team is as important as decision by the caregivers. However, experience may dull clinician judgment and they require regular reassessment and reappraisal. Clinical authority can be inevitably fallible due to clinical decision can just be based on uncertainties. Our upbringing, experience and training are different, thus this lead to different recommendation and decision to a different clinical context [2].

In contrast, parents experience and authority could be based on the side of person who is suffering. The decision reflects weighted wisdom of treating children and may also as a result of emotional reaction such as sadness which accompanied with courage. Parents' position as the caretaker for their children is unique and regarded vital part of responsibilities [2].

In general, patient's autonomy has to be respected and this is similar to parental autonomy unless the decision clearly against the moral and ethical decision [3]. Respecting parents' autonomy, though their experience and background are rather different, means to allow parents as individual unit to make their decision. The difficulties when one of the parents makes a conflicting decision or both making conflicting decision against the medical decision. This would require further negotiation as to which route is best to avoid jeopardizing between the parental and doctor relationship.

\section{Zone of parental discretion}

Children cannot be recognized as incompetent adult for the purpose of decision making. Children may have cognitive capacity depending on age and development, but in syndromic children, this capacity may be limited. The typical 'best interest of the child' concept may not be adequate because it does not allow reflection on the child's interest. Parents should be allowed to argue and prioritize the interest of the family over the interest of individual child[4], as in this case. Zone of parental discretion referred to tools which allow parents decision even doctors disagree with the parents on the ground of child best interests. It is a grey area whereby when best interest is vague and open to interpretation, interest of the parents, sibling and family must be taken into consideration. This is bounded by the point of harm being done to the child, rather than nonmaximization of the benefit[4].

\section{Rights of children}

Children are not miniature of an adult. Malaysia has enacted Child Act 2001 that provided every child with entitlement to protection in all circumstances regardless of colour, religion, ethnicity, sex, language and social background or physical, mental or emotional disability. The provision covers child protection and should be based on non-discrimination, right to live and survival, best interest of the child and respect for the child's view [5].

In our case, despite limited mental capacity in a Down child, we believe she still has the right to live and survive. The surgical correction was meant to alleviate physical disability; however, the future prediction of successful treatment outcome cannot be confidently forecasted. Her parents decided not to proceed with any interventional procedures apart from ventilator support and tracheostomy. Parental judgment and decision was accepted despite overwhelmingly opposition from the 
multidisciplinary team's recommendation. Is this considered as parental neglect? We believe, considering parental socioeconomic and cultural context, this is within the framework of zone of parental discretion as long as there is no harm done to the child.

Community ethics can be challenging when the child was discharged home. Some of the decision made by parents for example refusal to use ripple mattress, or refusal of gastrostomy as feeding option, or making decision without consulting medical personnel, can be dangerous. Monitoring family dynamic is essential to ensure there is no element of neglect to the patient and stress related condition as a result of parent's position to function in different role such as nursing care while at home. The use of virtue ethics which focuses on moral agent rather than rightness of an action perhaps is a better framework when patient is at home. This would include trustworthiness, integrity, discernment, compassion and conscientiousness [6]. Understanding of social and interpersonal nature of human being influences moral justification, thus giving meaning to our life existence and can give different dimension of opinion. Other influential factors include practical wisdom, emotional perception and motivation which determine the outcome of the decision process.

\section{Future palliative issues}

Following parents' decision for not allowing corrective surgery, the patient has ended up being bed bound for life. It is important to consider palliative care support as part of the support in the community. Preparation has been made to equip parents with skills to manage ventilator, nursing care, financial aid, counseling support, transferring of skills like basic life support and emotional strength.

This has to be assessed at different trajectory of life considering personal, family and medical needs. Community network has to be proactive looking to alleviate the suffering and controlling medical symptoms of the patient. The difficulty may arise again from parental refusal and against most of the medical advice. Again conflicting interest may resurface and as practitioner, we need to have boundary and not to be judgmental on parental decision as long as harm is not done on the patient. Caring and compassion should be one of the agenda to ensure humanistic side of care can be given to the patient.

Children's health awareness, in particular for the parents, need to be seriously educated by the policy makers in this country. Major focus usually directed at the prevention level rather than treatment of disease. Improving partnerships between stakeholders will ensure that everyone has a role to play towards betterment in children's health. Improving the children's health will require parents to change their routines, habits and paradigms. These changes will take time and requires a combination of public education, community development and healthy public policy.

\section{Suggested approach to the case}

Communication has become a fundamental aspect of patients' care and often become suboptimal due to fear of uncertain parents and patients response. Poor communication has led to poor clinical care, diminished trust and unsatisfied with the treatment. ICE (Idea, Concern and Expectation) approach has been used extensively in teaching and education. In medicine, the approach tackles on understanding the idea behind parental decision making, their concern on medical and psychosocial aspect and expectation of the medical treatment given to their children. It is vital to have a picture of their idea (I), concern (C), expectation (E) and answer this from their perspective. Effective communication approach must consider important factors such as being a good listener, negotiating appropriate agenda, being empathy, respecting and understanding concerns from parental eye views.

\section{Conclusion}

The case illustrates the difficulties faced by healthcare professionals when dealing with patients who have complex medical problems. The changing decision making in clinical context 
are perhaps as a result of different ethical understanding. Bioethics decision making in children is made largely by proxy especially by their parents. It is important to prepare parents with sufficient knowledge and time prior to final decision making. Zone of parental discretion is an important area whereby parents are allowed to make decision in spite of against medical suggestion. The only boundary, if harm is made, then it is the role of the doctor to take over on clinical decision making.

The ethics whilst patients at home can be somehow complex. We use virtue ethics and the principle of Islamic shariah[7] to allow appropriateness of medical management in the community. Despite the grey area mentioned, it is vital to keep connected with the family to allow communication and effective engagement of knowledge. This will strengthen doctorparents relationship and to have agreed resolution for the patients' sake. Factors like family influence, socioeconomic priority and societal factors have to be considered as part of the virtue ethics. Although virtue ethics may not be a fundamental framework for the above scenario, however, emotional, spiritual, psychosocial elements is paramount to the evolving concept of patient's care.

\section{Reference}

1. Wilkinson D. Is it in the best interest of an intellectually disabled infant to die? J Med Ethics 2006; 32: 454-459

2. McHaffie HE, Laing IA, Parker M, Mc Millan J. Deciding for imperiled newborn: medical authority or parental autonomy. Jour Med Ethics.2001; 27:104-109

3. Kumurasamy V, Ahmad Fairuz M, Taib F, Mohammad Najib MP, Mohd Nazri S, Norzila Z, Razlina AR, Rifqy Setyanto M, Siti Hawa A, Ch'ng TW, M Amalia, Nor Azwany Y. Autonomy to refuse: Please doctor I want to fast, I don't want my medications. 2014. EIMJ: 6; e66-e69.

4. Gillam L. Children's bioethics and zone of parental discretion. Monash Bioethics Review. 2010; 29: 1-3

5. Taib F. Invisible, vulnerable and marginalized children in Malaysia. MJPCH Online Early 2011: 18

6. Gardiner P. A virtue ethics approach to moral dilemmas in Medicine. J Med Ethics 2003; 29: 297-302

7. Gatrad AR, Sheikh A. Medical Ethics in Islam: Principles and practice. Arch Dis Child 2001; 84: 72-75 